\title{
فتح الله غولان: صوفي تركي في زمن العولمة
}

\section{* صالح محمد نصيرات}

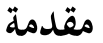

مع قيام الجمهورية التركية العلمانية بزعامة كمال أتاتورك في مطلع القرن العشرين، مرت تركيا: الشعب والدولة بالكثير من التغييرات التي طالت كافة صعد الحياة: السياسية، والاقتصادية، والفكرية، والثقافية، واللغوية. وقد كانت هذه التغييرات مثيرة وعميقة؛ ذلك أها لم تطل ظاهر الحياة وأشكالها، بل تعدةها إلى الباطن أيضا. واشتملت على تغيير في التركيبة النفسية والعقلية وحتى المظهرية الشكلية للإنسان التركي. وتحكمت في حياة المجتمع نخبة غريبة عنه، حاولت التحكم في اسم الشعب ورسمه.

ومع عمق التأثير الذي فرضته هذه النخبة، فإن ردود الفعل، كانت عميقة أيضاً. وفي هذه الورقة سنقدم قراءة لواحدة من الحركات الإسلامية التي نشأت في ظل الحكم الجمهوري. هذه الحركة التي ترتبط بالشخص أكثر من ارتباطها بالفكرة، هي حركة الشيخ فتح الله غولان. وتمدف الورقة إلى تقديم وصف وتحليل لهذه الحركة وتحليلها والظروف التي نشأت فيها والدروس التي يمكن الاستفادة منها. ولذلك ستعرض الورقة نشأة الحركة، والمبادئ الأساسية لها، والأثر الذي تركته الحركة على المجتمع التركي، ورؤية الحركة في إطار التطور التاريخي للحركات الإسلامية التركية من خلال العلاقة بين هذه الحركة وحركة الشيخ سعيد النورسي (1960-1877)

\section{فتح الله غولان وحركته}

ولد الشيخ فتح الله غولان عام 1938 في إحدى قرى محافظة أرضروم، 1 في عائلة متدينة. فقد كان والده الشيخ رامز أفندي من أوائل الذين ذهبوا إلى الحج بعد أن رفع أتاتورك القيود عن هذه الشعيرة. وكان 
لشيخ البلدة محمد لطفي أفندي أثر كبير في حياته، حيث يقول" أستطيع أن أقول أنني مدين للشيخ لطفي بقسم كبير من مشاعري وأحاسيسي وبصيرتي، لما كنت أسمع وأرى منه". أما أمه فقد كان لها شأن كبير في تربيته، حيث كانت تعلمه القرآن مع نساء القرية حتى حفظ القرآن في سن مبكرة جداً. 2

وقد كان لوجود شيوخ الصوفية واهتمام أسرته به، أثر بالغ في إيقاظ النزعة الدينية فيه، وإقباله على تعلم العلوم الإسلامية واللغات الإسلامية كالعربية والفارسية. وقد اطلع في وقت مبكر على رسائل الشيخ بديع الزمان النورسي، مما أسهم في تفتيح مداركه على أهمية العمل للإسلام بروح وثابة وجدية عالية، إضافة إلى أن لدعوة النورسي إلى الاهتمام بالعلوم الطبيعية والاستفادة منها في تدعيم الإيمان، الأثر الواضح في تبني غولان لخط المزج بين العلوم الشرعية والعلوم الدنيوية وعلى رأسها علوم الطبيعة.

وقد بدأ غولان عمله موظفاً في وزارة الشؤون الدينية التركية في أوائل الخمسينيات من القرن الماضي، وفي عام 1958 انتقل إلى قرية أدرنه إماماً لمسجد، وفي عام 1966، انتقل إلى إزمير، المدينة الساحلية والمشهورة بتحررها. ويبدو أن نشاطه الدعوي وقدرته على التأثير فيمن حوله جعلت الحكومة التركية تعتقله عام 1971، بتهمة إنشاء تنظيم ديني معاد للنظام العلماني العقيدة الرسمية للدولة التركية. وفي عام 1980 وبعد الانقلاب الثالث لم يعتقل الشيخ غولان رغم المضايقات التي كانت تلاحقه وأتباعه. وفي ظل حكومة أوزال، كان للشيخ عهد جيد، حيث اتسع بجال الدعوة أمامه وقام بالانتقال بدعوته إلى مرحلة جديدة ومهمة خصوصاً في ظل الانفتاح الاقتصادي لتلك الحكومة. 3

إن استخدامنا لكلمة "حركة" في هذه الورقة، لا تعني المفهوم التقليدي الذي يعني وجوداً تنظيمياً بهيكلية معينة كالحركات الإسلامية والشعبية الأخرى، ولكنه استخدم لغرض الإشارة إلى الاتحاه العام لتجمعات شعبية، وإن كانت ليست على درجة معينة من التعقيد التنظيمي والهيكلي. ولذلك يطلق بعض الباحثين على أتباع غولان لفظ" المجتمع" أو" الجالية" أو التجمع. وكلها ألفاظ تعني في مجملها عدم وجود

$$
1
$$

$$
2
$$

3 Bulent Aras. “Turkish Islam's Moderate face”. Middle East Quarterly. Volume v, 3, (September 1998) 
هيكلية تنظيمية. وهذا يجعلها أقرب إلى المفهوم الصوفي، حيث تجتمع الحركة في شخص الشيخ الزعيم دون مؤسسات تحكم هذه الحركة. ولذلك لا نجد أثراً لوجود مكاتب تنفيذية أو مجالس شورى أو غيرها من

$$
\text { المؤسسات ذات الدلالات الحزبية. }
$$

نشأت حركة فتح الله غولان في ستينيات القرن الماضي متواضعة بسيطة على يد معلم القرآن الكريم في

مدينة إزمير التركية ذات الجمال الآخاذ، وغدت خلال عقود، واحدة من الحركات الإسلامية المتميزة في منهجها، وأساليب عملها، وحتى فلسفتها التي تشكل الأساس النظري لها.

وقد جاء تميز الحركة من تميز المنظرّر والمكان والزمان. أما المنظر المنشئ فهو معلم القرآن الكريم فتح الله غولان، الذي يجمع بين أمور كثيرة جعلت منه شيخاً ومفكراً ومربياً وإن كانت الصفة الأخيرة المتصلة بالتغيير السلوكي للفرد وبالتالي الجماعة أكثر ما يميز غولان.

لم يكن غولان الذي نشأ في ظلال العلمانية التركية أكثر من شخص تركي عادي، أمله أن يمارس شعائر دينه بسلام. ولكن الرجل وبعد اطلاعه على علوم الدين المختلفة، أدرك أن دينه لا يقبل منه أن يمارس هذا الدين مكتفياً بالحد الأدنى كما يفعل كثير من المسلمين. ولذلك لم يقنع بهذا الحدد الأدنى، بل رأى كي أن الفرصة سانحة للتقدم بمشروع تربوي يمكن أن يكون بعيد الأثر في الحياة التركية بل والإنسانية، وهذا ما حصل بالفعل. فمن خلال فهمه للواقع التركي، استطاع غولان أن يتقدم بمشروعه خطوات كبيرة تبيّن للمتأمل والباحث وأولئك الساعين للتغير كيف أن النفس المنطوية على حب الإسلام والبشرية وتفهم الإسلام فهماً سليماً، وتريد أن تتغلب على كل عوامل اليأس وتتسلح بروح الأمل تستطيع أن تعمل وتغير حتى في أحلك الظروف وهذا ما سنراه تالياً. فالحركة نشأت في أكثر بلاد العالم نقداً للدين وتقييداً لحركته. حيث تميزت العلمانية التركية -الأتاتوركية- بهجومها الصارخ على التدين ومحاولة القضاء على الدين شكلاً وموضوعاً. نشأت في بلد كانت العلمانية في أوج سطوتا، والتدين والمتدين لا يلقى سوى الصدود والتعنيف

$$
\text { والحرب الشعواء. }
$$

أما الزمان، فهو غداة الانقلاب الثاني للجيش على الحكومة التي حاولت تقديم بعض التنازلات لصالح الدين بعد الفشل الكبير في محاولاما الدووبة للقضاء عليه. فمع مندريس كانت بداية التغيير. والتغيير الذي 
أخذ بعداً شكلياً في البداية لم يكن متصوراً وسهلاً على الحكومة والشعب. فقد تلقى الشعب التركي التغييرات بالسجود في شوارع استانبول عندما سمع لأول مرة بعد الأتاتوركية صوت المؤذن يصدح بالعربية بعد أن فرض عليه أن يسمع الآذان بالتركية.

\section{البيئة التي نشأت فيها الحركة}

من الواضح أن مشكلات تركيا الأساسية والتحديات التي تواجهها ليست اقتصادية أو عسكرية أو اجتماعية فحسب، بل إن التحدي الأكبر هو حالة التذبذب التي تعيشها في محاولتها الدوؤبة للبحث عن ذاتما وإيجاد مكان لها في عالم اليوم. فتحدي الموية هو التحدي الأكبر لتركيا الحديثة.

فالعلمانية التركية ممثلة بالفلسفة الكمالية لتركيا ما بعد الخلافة، اعتقدت أن خلع الإسلام من الجذور والتوجه شطر أوروبا وتغريب الشعب التركي هو السبيل الأمثل إذا ما أريد لهذه الدولة أن تكون متقدمة وعصرية في آن. أما الإسلام وتقاليده الذي يشكل في الواقع ضمير الأمة التركية فإنه عقبة في وجه ذلك الزحف نحو المدنية والتقدم. ولأن الإسلام لا يمكن علمنته أو خصخصته! فإن الحل الأمثل هو التحكم فيه وجعله أمراً شخصياً لا يخرج من نطاق الذات.

ولذلك اختطت العلمانية التركية خطاً موازيا للعلمانية الفرنسية التي تعتقد أن الدين يجب أن يكون تحت السيطرة وأن لا يكون له دور في الحياة العامة، فالإقصاء والتهميش، بل التدمير المنظم للدين هو الأسلوب الأمثل في نظر علمانيي تركيا للقضاء على الرجعية! وقد كانت ردة الفعل الإسلامية على هذا المنهج هو الانسحاب المؤقت من الحياة العامة، ولكن فيما بعد رأينا نوعاً من التكيف والتفاوض من قبل الإسلاميين، حيث يشير تاريخ الحركات الإسلامية بوضوح إلى قدرة على التكيف وعدم الركون إلى السلبية 


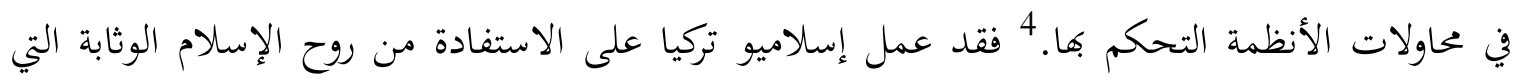
تغذي روح المقاومة لدى المسلمين، وكذلك محاولة التغيير من خلال أطروحات المواءمة بين الإسلام والحداثة. ولفهم الخلفية العلمانية لتركيا الحديثة، لابد من فهم الإطار الزمني لهذه الفكرة. فمتابعة هذه التطور

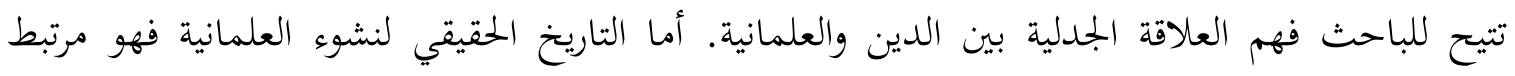

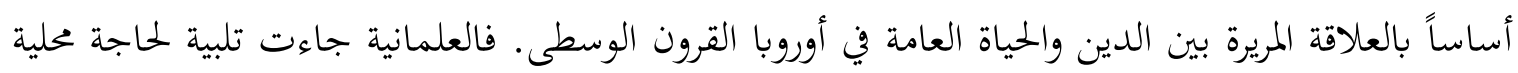

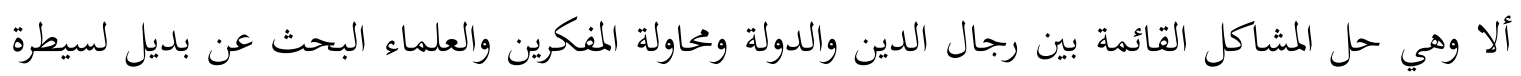

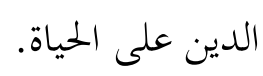

ولعلّ النموذج العلماني في تركيا قد فتح باباً بل أبواباً للصراع بدل أن يأتي بفرص الاستقرار والسلام.

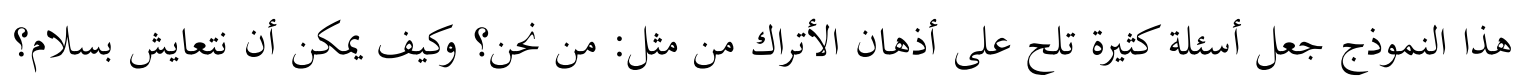

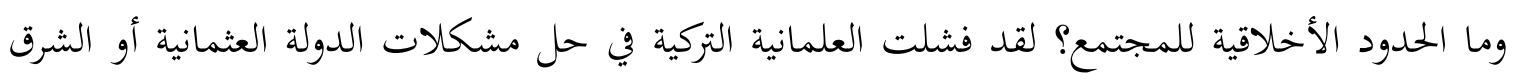

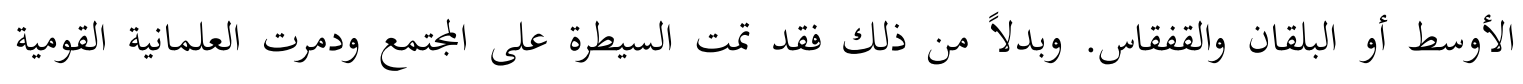
الكمالية الصفة المتعدة للإثنيات في الجتمع التركي بالتخلص من الأقليات اليونانية والمسيحية والمقوق الثقافية للأكراد.

تأسست العلمانية التركية على الفلسفة الوضعية؛ فالتقدم مبني على الإميان المطلق بالوضعية لقيادة

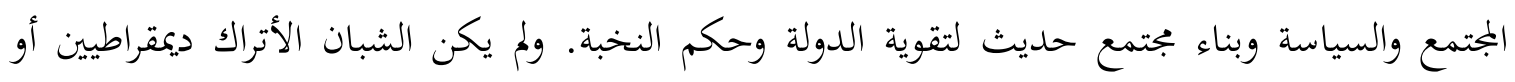
ليبراليين، كما ظهر في الممارسات اليومية لهم. وتقوم العلمانية الكمالية على مبادئ ستة هي: القومية، العلمانية، الجمهورية، الدولة، الإصلاح، والشعبوية. هذا كله لم ميل مشكلات تركيا بل تفاقمت تلك المشكلات وبقيت العلمانية في نظر الشعب التركي

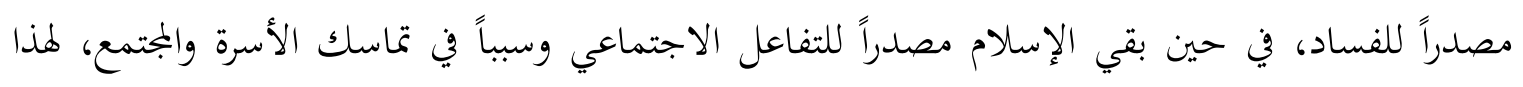

4 Bulent Aras. “Turkish Islam's Moderate face”. Middle East Quarterly. Volume v, 3, (September 1998).

$5 \quad$ Ibid. p. xviii 
فالافتراق بين السياسة والأخلاق الاجتماعية سبب مشكلات جمة للمجتمع التركي. وبقيت العلمانية في إطار النخبة الحاكمة وابتعدت الأمة التركية أكثر فأكثر عن تلك النخبة لأن تلك الأيديولوجية لم تنبع من داخل المجتمع التركي بل فرضت قسراً، والفشل أمر طبيعي لمثل هذه المحاولات. والنتيجة نشوء حركات إسلامية مثلت النقيض المباشر للعلمانية والحداثة المستوردة.

وقد ساعد على نشوء الحركات الإسلامية أمور عدة منها: انتشار التعليم والهجرة إلى المدن والمشاركة السياسية حيث استخدمت شبكة العلاقات الدينية في السياسة، كما أن البحث المستمر عن قيم للتأقلم مع التحديات الحديثة للهوية والأخلاق ساهم في نشوء تلك الحركات.

لقد طبق الإسلاميون الأتراك مقولة التأقلم مع الواقع والاستفادة من الفرص أفضل تطبيق. ولعل هذا الموقف يطرح تساؤلاً حول مدى مرونة الإسلام كنظام حياة وتفاعله مع الواقع الجديد الذي فرضته التحولات

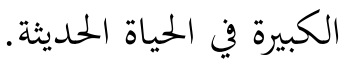

التطور التاريخي للحركات الإسلامية التركية وموقع حركة الشيخ غولان منه

لا يمكن فصل حركة الشيخ فتح الله غولان عن الجهود الكبيرة التي بذها خلال أكثر من نصف قرن كثير من العلماء والمفكرين الأتراك لمجاجة الطغيان الكمالي على الحياة الإسلامية التركية. ولعل أبرز ما يميز حركة الشيخ غولان هو أها امتداد وتحديد لحركة النور الإسلامية التي كان لزعيمها الشيخ سعيد النورسي الفضل الأكبر في إيقاظ الشعور الديني والحماس للإسلام ولبعثه في الحياة التركية. ولذلك يمكن النظر إلى حركة الشيخ غولان كمرحلة من مراحل التطور التاريخي لحركة الإسلام في تركيا. وقد كان الشيخ سعيد النورسي من أوائل من تفاعل مع الحياة الجديدة وحاول الاستفادة من الطاقات المخزونة في وعي الشعب التركي عن الإسلام. فالإسلام في نظره نظام معياري ونظام أخلاقي يحدد معايير الخطأ والصواب في حياة الفرد والمجتمع. كما أنه قوة داخلية لبناء النفس وتقوية الذات في مواجهة أمراض المجتمع العصري.7

6 Yavuz \& Esposito. Ibid.,

7 Yavuz, H. Islam in the public sphere, in Yavuz \& Esposito. Ibid. P.4. 
من المهم للقارئ أن يعرف أن النورسي مر بمراحل ثلاث وقد أطلق النورسي علن نفسه: سعيد القديم وسعيد الجديد وسعيد الثالث. هذه المراحل الثلاث تعبير عن حالة الوعي التي مر بها هذا المفكر الفذ. فقد رأى في بداية الانقلاب الأتاتوركي أن الشبان الأتراك بما أعلنوه من إصلاحات يمكن أن يكون سبباً في بتحيد الفكر الديني. ولكن الحملة المنظمة التي تلت ذلك جعلت النورسي يترك الشبان الأتراك ويعود لممارسة العمل الدعوي والتربوي. وقد رأى أن مهمته تتمثل في حماية التفكير من التعصب والناس من الإلحاد. ولذلك فقد هدفت كتاباته الكثيرة إلى رفع حالة الوعي بين أبناء الشعب التركي بإعادة الذاكرة الجمعية لهذا الشعب عن طريق إعادة الدين للمجتمع الذي يمثل لحمته وسداه. كما أنه تطور ليجعل هدفه بناء مجتمع مستقر من خلال قناعته بأن التغيير يكون بالفرد ثم يتطور صعداً إلى المجتمع الأكبر. ورأى أن المشاركة السياسية سبب في التغيير الإجتماعي. لكن سعيداً الجديد أي المرحلة الثانية من عمره تمثلت بالانسحاب من السياسة والتفرغ للكتابة حيث أنتج الكثير من رسائل النور التي تم نسخها بأيدي مريديه الذين نشروا فكره على نطاق واسع في الأناضول وفي المرحلة الأخيرة من عمره مال إلى تأييد الحزب الديمقراطي.8 8

تنطلق مبادئ النورسي من الفهم الجيد للقرآن الكريم، حيث يرى الإممان فطرة كما في قوله تعالى

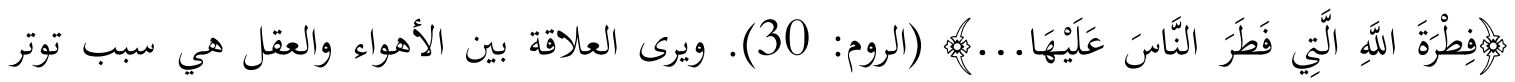
الإنسان، ولا حلّ لهذا التوتر إلا بالإيمان بالله سبحانه وتعالى. وغياب الإيمان سبب الحروب والخلاقات على رئل مستوى المجتمعات والدول. ولذلك فما قدمه النورسي هو خريطة للمعاني أي دليل عمل للمسلم للانخراط في الحياة العامة بشكل نقدي ذكي. من الأمور المثيرة التي اعتقدها النورسي أن العالم يشيخ بينما القرآن يزداد حيوية وشباباً. كما أن اهتمامه بالعلم لم يجعله ينظر إلى القرآن ككتاب اكتشافات علمية، بل رأى في القرآن وآيات الله سبحانه في الكون سبباً في الدعوة إلى مزيد من الاهتمام بالعلم الطبيعي وتسخيره لفهم القرآن. ومن المهم أن نرى أن النورسي لم يقصر كتاباته على فئة دون أخرى، بل تعدى ذلك إلى المجتمع الكبير، حيث استفاد من التطور الذي حدث في الطباعة والتي كانت سبباً في نشر أفكاره بين الجمهور التركي بمجمعه. 
تركزت نظرية النورسي لحل المشكلات التركية بنظرة متدرجة للتحول تبدأ برفع وعي المسلم وتطبيق الدين في الحياة وتحكيم الشريعة. وكانت رؤية النورسي للدولة تنطلق من فهمه للإسلام وهو أن الدولة خادمة للأمة وأن أسس الدولة يجب أن تكون مبنية على الحرية والعدل واحترام الكرامة الإنسانية وإرادة الشعب. ولذلك فإنه قدم الحرية على الخبز ودلالة مقولته التالية كبيرة جداً مقولته الشهيرة " أستطيع العيش بلا خبز ولكنني لا أستطيع العيش بلا حرية" فبالحرية يعيش الإنسان كما أراده الله مختاراً ومسؤولاً، وبدوها يصبح عبداً للآخرين. وهي استمرار لفكرة الدفاع عن الحرية في الفكر الإسلامي منذ ظهور الإسلام إلى اليوم. ويبدو أن غولان قد حمل نفس الأفكار المتعلقة بالدولة ولكنه لا يزعم أن حركته ستؤدي إلى بناء الدولة الإسلامية في تركيا. فنرى أحياناً أنه يتحدث عن الديمقراطية والعلمانية كأساسين للدولة الحديثة وأن تركيا بنيت على هاتين الدعايتين. ولكن نقده اللاذع للعلمانية وتافت المشروع العلماني في تركيا واتحامه للعلمانية بأهما أنتجت إنساناً غير متوازن وسببت الكثير من المشكلات لتركيا وخصوصاً في علاقتها بالدين، هذا النقد لا يجعلنا نعتقد بأن غولان يؤمن تماماً بما يقال عنه. ونرى أنه مع النظرة المتدرجة للانتقال بالأمة التركية إلى مرحلة الاختيار كشيخه النورسي الذي يقول: "بعد إعادة وعي الشعب بالإسلام، عليه اختيار

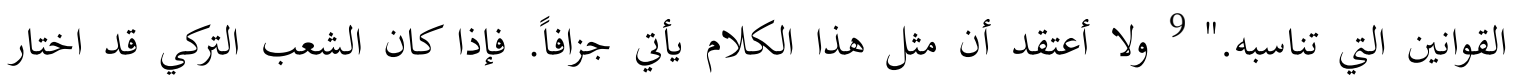
الإسلاميين مرتين عام 1997 عندما فاز حزب الفضيلة بالانتخابات البرمانية وجاء أربكان رئيساً للوزراء، وعندما فاز رجب اردوغان وحزبه بالانتخابات في عام 2003، فإن هذا الاختيار جاء نتيجة الوعي بالإسلام إضافة إلى أمور أخرى. أما مطالبته بحياد الدولة بتحاه الدين عموماً فلاعتقاده في رأينا أن الجيش بسطوته الحالية لا يمكن أن يقبل للإسلام وأحكامه أن تكون النافذة في الحياة التركية، لذلك فإن الحياد المطلوب أمر مهم جداً كي تتقدم كل الفئات ببرابجها -ومن بينها الإسلاميون- للشعب التركي والراجح أن الشعب سوف يختار الإسلام. وعندما يتحدث عن أسس الدولة فإنه يراها مطابقة للإسلام. فأسس الدولة عنده هي: العدل والحرية واحترام الكرامة الإنسانية واحترام إرادة الشعب. هذه المبادئ التي ينادي بها غولان 
هي عينها المبادئ التي تنادي بها الحركات الإسلامية المعتدلة في العالم الإسلامي. ويقول يفوز : "إن الهدف الأساس لغولان هو مجتمع أساسه الشريعة."10 وهو أمر لا يتحقق إلا في ظل الحرية وحكم القانون.

وقد يلاحظ البعض أن غولان في عدم مواجهته للدولة التركية وغض الطرف عن حل الأحزاب الإسلامية كالرفاه وإبعاد أربكان عن الوزارة عام1997، يعني رفضه للحكم الإسلامي أو المحاولات التي تقوم بها الأحزاب الإسلامية لتقديم النموذج الإسلامي دليلاً على صراع بينه وبين الإسلاميين الآخرين. وما يمكن فهمه هنا هو أن الاختلافات في الآراء بين الإسلاميين موجودة في كل بلاد العالم الإسلامي. ولكن خشية غولان أن يجهض المشروع السياسي والتربوي الإسلامي بيد الجيش وضياع الفرصة التاريخية لتبليغ الدعوة الإسلامية وعودة تركيا إلى الفوضى السياسية كما حصل في سبعينيات القرن الماضي، هو الذي يدعوه إلى اتخاذ تلك المواقف، بدليل أن الجيش لم يسمح له بالاستمرار في دعوته ونفاه خارج بلاده خوفاً من هذا المشروع النهضوي الجديد. ولذذا فهو مع الوجود الفعلي للدولة لأن غياب الدولة معناه الفوضى والاقتتال الداخلي. فغياب الدولة يعني عدم الاستقرار ويعني النزاع الفكري. فلو تخيلنا تركيا بلا دولة فإن أفار الدم ستسيل بسبب الصراعات بين الأحزاب والطوائف والجماعات المختلفة. 11 ويرى أكتاي أن غولان في تفضيله الاستقرار على غياب بعض الحريات منسجم مع فقه أهل السنة الذين مارسوا ذلك لقرون كثيرة. 12

\section{المبادئ الأساسية لحركة فتح الله غولان}

من الواضح أن الحركة جاءت في ظل ظروف تركية محلية مناسبة للتوسع والتمدد، إضافة إلى أن منهجية غولان المبنية على عدم مجاهة النظام العلماني القائم وتحديه سياسياً، بل دعمه أحياناً كما حصل في انقلاب 1980 والانقلاب الثاني على حكومة أربكان عام1997. فقتح الله غولان لا يهدف من وراء حركته بعث الدولة العثمانية أو بناء دولة إسلامية، ولكن جاء ليبني نظاماً تعليمياً أساسه الأخلاق الفاضلة النابعة من الإسلام والقيم الإنسانية. 13 ولذلك وجه اهتمامه إلى الشباب في محاولة منه لبناء المجتمع المتدين

10 Ibid., p. 11

11 Can, E. Fethullah Gullen ile Ufuk Turu.13th ed. Istanbul: A.D.

12 Aktay, Y. Diaspora and Stability. In Yavuz and Esposito, ibid, p. 153.

13 التصوف، موقع الشيخ غولان. 
المحافظ متوسلاً ببناء المدارس والمعاهد والجامعات. في تلك المدارس التي أنشأها، أنشأ أيضاً بيوت النور وهي مساكن الطلبة الذين يعيشون معاً، حيث يمارسون أنشطتهم الدينية والعلمية في جو نظيف. وهدف غولان من هذا هو حفظ الشباب من إغراءات النظام العلماني ومجتمع الشهوات. ولذلك يعتقد غولان بأن زرع أخلاق التسامح وحب الله والمسؤولية واحترام الذات الإنسانية والتضحية في سبيل المجموع أخلاق إسلامية وإنسانية. ولذلك فإن أهم عناصر خطته في العمل أن يؤسس لحب الله في نفوس الشباب والطاعة المطلقة له، وبناء الأمل بولادة مستقبل زاهر للأمة التركية المسلمة.

في المرحلة الثانية هدف إلى خلق ما أسماه ب "الجيل الذهبي". حيث استفاد من فرص المجتمع الجديدة المتمثلة بالانفتاح والعولمة في بناء شبكة إعلامية كبيرة وبناء مؤسسات مالية واقتصادية لدعم توجهاته التربوية والتعليمية. وكان تخصيص التعليم في تركيا عام 1983 فرصته لبناء مجتمع منسجم منضبط على إيقاع الأخلاق الإسلامية. ولذلك فهو يقول عن منهج التعليم في مدارسه: دين بلا تعليم علمي سيؤدي إلى التطرف، وتعليم بلا دين يؤدي إلى الإلحاد."

أما منهجه الوعظي فيكشف عن قدرة متميزة في ربط المستمعين والمشاهدين له بكم من خلال استخدامه لأسلوب القصص. حيث يركز في خطابه على أن الرسول الكريم محمد صلى الله عليه وسلم هو النموذج الأكمل لبناء الإنسان الكامل. ولذلك فهو يلح على تلاميذه ومستمعيه بالتأسي بأخلاق النبوة. هذا الخطاب العاطفي الممزوج بالقصص النبوي والقرآن وبروح معتدلة، جعلت الكثيرين يسيرون إليه ويكونوا من رواد مجالسه. وهذا بحد ذاته نجاح كبير له في ظل نظام علماني يمسك بتلابيب الحياة ويحصي على الناس كلامهم ومواقفهم.

وييدو أن فتح الله غولان يفكر بطريقة منهجية فهو ينتقل من مرحلة لأخرى دون أن يكون الانتقال ملحوظاً. فهو ينتقل بعد أن كان تركياً محلياً إلى تركي عالمي. لذلك فهو مهتم كثيراً بالجاليات التركية في أوروبا وأمريكا والشعوب التركية في آسيا الوسطى من خلال بناء المدارس والحث على الأخلاق الفاضلة.

ولذلك يمكن رؤية فهمه لمفهوم التدرج في الدعوة والصبر عليها" ومن غير المتصور بداهة أن يتغير كل شيء في مجتمع يتعرض منذ قرنين إلى الانقلاب في القيم والتعويد على العوائق والمثبطات بحملة واحدة من 
خوارق الكرامات! فليس يسيراً أن يحل الإيمان محل الإلحاد، والانضباط محل الانفلات، والنظام محل الفوضى، والأخلاقية محل اللاأخلاقية."14

هذه الحركة لم تكن بعيدة عن رصد الإعلام العلماني الذي أخذ يشن هجمات متتالية عليه، متهما غولان بالرجعية ومحاول تقويض أسس النظام العلماني. لأن غولان يعتقد بأن الدولة خادمة للشعب وليست رقيباً عليه، حيث يقول" ليس للدولة أن تكون علمانية أو دينية، وليس لها أن تتبنى فلسفة أو تمنع أخرى، ولكن عليها أن تكون محايدة وتعطي الحرية للناس ولا تمنع أحداً من المشاركة السياسية". ولذلك يمكن تلخيص مبادئ حركة غولان في:

الإسلام نظام أخلاقي يجب بعثه والتمسك به. ويمكن للإسلام أن يقدم بدائل لكثير من الخيارات المقدمة للناس في الإعلام والاقتصاد والسياسة. والدين أفضل وسيلة لزرع أخلاق التسامح والحب. والأمل مفهوم إسلامي وليس للمسلم أن ييأس. والعمل الإسلامي يجب أن ينظر إلى الواقع وينطلق من فهم جيد له.

أما وسائل العمل عنده فهي؛ التربية في المدارس الإسلامية المنتشرة في بلاد كثيرة لحماية المسلم من فساد النظام؛ وبيوت النور، حيث يجتمع الطلبة المسلمون في جو إسلامي بعيد عن إغراءات الشارع؛ المخيمات التربوية والتي يعش فيها الطلبة المسلمون لأسابيع يمارسون عباداتم بحرية؛ استخدام كل وسيلة إعلامية من الصحيفة إلى المجلة والتلفاز والإنترنت؛ بناء المؤسسات الاقتصادية التي تخدم وسائل نشر الدعوة؛ و تأسيس الروابط والاتحادات المهنية كرابطة الكتاب والصحفيين المسلمين وغيرها. هذه الوسائل في واقع الأمر لا تختلف كثيراً عن وسائل الكثير من الجماعات الإسلامية في المشرق العربي وشبه القارة الهندية. الصوفية في حركة غولان 
السؤال الذي يتبادر إلى الذهن هو ما إذا كان الشيخ سعيد النورسي صوفياً، وحركته ذات بعد صوفي وإن لم تكن طريقة صوفية بالمعنى التقليدي، فهل تأثر غولان بالنورسي يجعل منه صوفياً؟ وإذا كان كذلك، فإلى أي مدى يمكن اعتبار حركة النور الجديدة صوفية بالمعنى التقليدي للكلمة؟

يعتقد زكي سري توبراك بأن مصدر الفهم الصوفي عند غولان هو " القرآن والسنة وكتابات المتصوفة خصوصاً "رسائل النور" للشيخ سعيد النورسي. ويعرف الشيخ غولان الصوفية بأها" الطريق الذي يسير في الفرد الذي تحرر من الضعف الإنساني ليحصل صفات ملائكية في سلوكه وأخلاقه مرضياً ربه، يعيش وفق متطلبات المعرفة بالله وحبه والنتيجة الشعور بلذة السعادة من تلك المعرفة والحب."15 وهذا التعريف يتضمن أموراً مهمة يعرفها المؤمن بالله. فالعلاقة بالله لا تكون مع الجهل، إذ لابد من المعرفة بالله سبحانه، وهو أمر دعا إليه القرآن الكريم من خلال الآيات المبثوثة في ثناياه والتي تدعو المؤمن للنظر والاعتباروبه أنفسكم، أفلا تبصرون. واختلاف الليل والنهار لآيات لأولي الألباب..... (آل عمران:190) كما أن المعرفة الباردة لا تكفي، بل لابد من الحب الكامل لله سبحانه، ومن هنا فإن عقيدة الإسلام مبنية على الحب المطلق لله سبحانه بلا شريك أو ولد. وتعريف العلماء للعبادة منطلق من هذا الفهم فهي أي العبادة عند ابن تيمية "كمال الحب

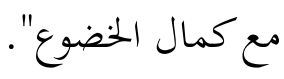
وبالنسبة للمفاهيم الصوفية التي تعد مخرجة من الدين كوحدة الوجود فيقول فيها غولان" إن الذرات لا يككن أن تكون جزءاً من الخالق، لأن القرآن يذكر أن المخلوقات آيات ودلائل على وجود الخالق."16 هذا الفهم المنطلق من القرآن والسنة مهم جداً للمسلم العادي. فالصوفية في نظر الكثير من المسلمين عزلة عن الحياة وتلذذ بالعبادات الفردية والهدف خلاص فردي. والإسلام دين لم يأت لهذا، بل جاء ليقرن الحياة بالآخرة، وليجمع بين الخيرين. كما أن النشاط الذي بدأه الشيخ غولان ينسجم إلى حد بعيد مع

${ }^{15}$ Güllen, 1999c p. xiv. In Sartoprake, Z. A Sufi in his own way. In Yavuz \& Esposito p.161.

16 Ibid., p 166 
الفهم الشامل للإسلام. ويستطيع المرء أن يدرك أن الكثير من الحركات الإسلامية التي لاقت نجاحاً بين العامة، كان للبعد الأخلاقي والسلوكي نصيب كبير. وفهم غولان ليس بعيداً عن الفهم الذي مثلته حركة الإخوان المسلمين التي انطلقت في أوائل القرن الماضي، فالتربية والتزكية ركنان مهمان في بناء هذه الحركة. كما أن النشاط العلمي والتربوي للحركة وكذلك مفهوم الخدمة العامة الذي يركز عليه الشيخ غولان.

والذي نريد أن نصل إليه، هو أن الفهم المشترك بين كثير من الحركات الإسلامية سببه وحدة المصدر:

القرآن والسنة. على أن الاختلاف أكثر ما يكون مصدره اختلاف البيئات والأولويات. فليس من المعقول أن يطالب غولان بإنشاء حركة إسلامية في مجتمع تحكمت فيه الدولة بالحياة الحاصة للإنسان وأحصت عليه أنفاسه حتى إنالم تختلف كثيراً عن النظام الشيوعي السوفيتي الذي حاول إلغاء الدين من حياة الشعوب

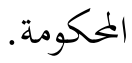

إن الشيخ غولان كما يقول عن نفسه بأنه ليس صوفيا، ولكنه يمارس التصوف، وأن حركته ليست طريقة صوفية، لا تختلف عن مقولة الإمام حسن البنا عندما ذكر أن حركته حقيقة صوفية وليست طريقة. وهذا من عبقرية هذين العلمين الذين فهما الإسلام فهماً وسطياً. كما أن مفاهيم غولان عن الجهاد وإحياء هذه الشعيرة المهمة تلغي فرضية أن الشيخ صوفي بالمعنى البحت. ففي معرض حديثه عن الجهاد يقول الشيخ" الموت الشريف.. يفضله المؤمن الحق على العيش الذليل.. الموت العزيز أفضل ألف مرة من العيش في عقر الدار في قلق واضطراب خوفاً من تسلط الظلمة علينا. هو هكذا إذا استغرق في بحر العرفان الرباني، ذلك المسلم العزيز الكريم، ولا يدرك هذا المعنى من يعيش حياة المقابر في الحياة... فلا ضمان لتطهير هذه الأجساد المليئة بالآثام إلا طريق الشهادة... البقاء في هذا الشعور والفكر، واغتنام الفرصة متى سنحت والتمسك به، والسعي للفوز بذلك الموقع المعلى مضطرباً اضطراب أبي عقيل.. نعم إن هذا هو أسمى غاية لكل من حمل أمانة دعوة الإسلام العظيمة، وينبغي أن يكون هذا. فالشهادة هي غايتنا ومطلوبنا وعشقنا...17" 
يرى غولان أن" التصوف هو طريق الوجدان الإنساني في فهم حقائق الإسلام، والإحساس بها. فمن

كانت حياته بعيدة عن الحياة العاطفية الإسلامية، فإنه لن يستطيع إدراك حقيقة التصوف"

التصوف هو درب البحث عن طريق القلب وعن طريق عين القلب عن الحقيقة الإنسانية التي تعجز

الفلسفة عن مد يدها نحوه...." و "التصوف هو عملية تصفية روح الإنسان وتطهره وتوحده مع ذاته، وبحاوز الزمان والمكان والوصول إلى أبعاد بجهولة. وهو الطريق الوحيد أمام كل فرد لكي يمر من الباب الذي فتحه

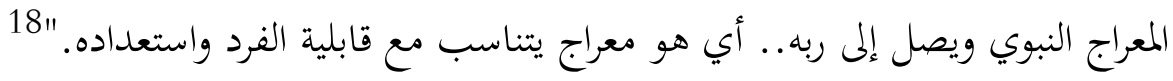

\section{التربية والتعليم في حركة غولان}

ولأن التعليم وسيلة غولان للتغير، فقد ركز على تبني فلسفة تربوية تؤمن بتجذير الدين من خلال بناء جيل متدين وقادر على المشاركة الفاعلة في الحياة العلمية العالمية. حيث يرى أن التعليم أساسه الدين والعلم، ولذلك فإن هدفه بناء جيل متشبع بروح الإسلام وقيمه ومتسلح بالعلم والمعرفة العصرية الحديثة.

وقد نشأت قناعات غولان بأهمية التعليم لما رآه من تناقض في النظام التعليمي التركي المبني في رأيه على عدة أنظمة متناقضة. فهو تعليم لا يقدم للخريجين تصوراً كاملاً للمستقبل ويكرس التفرقة في المجتمع ولا ينشئ جيلاً يتخلق بالأخلاق الفاضلة. فالمدارس العلمانية لا تستطيع تحرير ذاتما من التعصب والأيديولوجيا، كما أن المدارس الدينية لا تظهر قدرة لمقابلة تحدي العلوم والتقنية، ولذلك فالمدارس الدينية تنقصها المرونة والرؤية الثاقبة للمستقبل والتخلص من الماضي أو أن تقدم بديلاً تربوياً لتحديات اليوم. 19

وقد كان لغولان نظرته السليمة في التفريق بين التربية والتعليم. فهو يقول" المدرسون كثيرون والمربون قلة، والمعلم والمربي كلاهما يقدم معلومات للطالب ولكن الفرق بينهما هو أن المربي هو الشخص القادر على مساعدة التلاميذ على إبراز شخصياهم التي تزرع التسامح والتفكير التدبر والضبط الذاتي وروح المسؤولية والقصدية." ويضيف غولان فيقول: "بدلاً من أن يوجه المدرسون المجتمع، سمحوا لأنفسهم أن يكرسوا نظاماً 
تعليمياً منفصلاً ومقيدا، وبدل أن يحتج المدرسون على إبعاد القيم الإنسانية عن النظام التعليمي، والذي يدرس في المنطق والأخلاقيات والروحانيات، نجدهم يتكيفون مع القيم الهابطة."20

ولذلك دعا غولان إلى نظام تعليمي يجمع بين المعرفة العلمية من جهة والأخلاق والروحانيات من جهة أخرى لإنتاج شعب متنور ذي قلب نابض بنور العلم والإيمان والدين وعقل يضاء بقيم العلم الإيجابي.

ولعل تأثره بموقف النورسي الذي كان يرى العلم والدين حلقتان تكمل إحداهما الأخرى، جعله يركز على ضرورة أن ينال تلاميذ مدارسه قسطاً كبيراً وحظاً وافراً من العلوم الطبيعية. ولذلك فالدين ليس غريباً عن المؤمن وهو وسيلته للتعرف على خالقه. ومن هنا فإن هدفه أيضاً أن يدير المؤسسات العلمانية شباب مؤمن متشبع بروح الدين وقيمه. وقد يبدو الأمر متناقضاً أو هكذا قد يفهم البعض، لكن الحقيقة هي أن معظم البلاد العربية والإسلامية علمانية بدرجات متفاوتة، ومؤسساتما علمانية من التعليم إلى الاقتصاد إلى السياسة، والحركات الإسلامية العربية وغيرها تحاول أن تكون جزءاً من النظام القائم ولكن من خلال تبني فلسفة إسلامية للحياة.

ولم يقصر الأمر على التبني النظري للإسلام في بعده التربوي كما يفعل كثير من المنظرين للتربية الإسلامية والتي كثيراً ما تختلط بالمفهوم الوعظي للتربية، وليس بالمفهوم الشامل الذي يقدم للمؤمن زاداً حقيقياً من خلال تقديم تعليم ديني ممزوج بعلوم عصرية تؤهل المسلم للعب دور جاد في بناء حياته وبجتمعة والحياة الإنسانية. ولهذا بنى الشيخ غولان وأنصاره مئات المدارس في تركيا وآسيا الوسطى وأوروبا وحتى دول ليس للوجود الإسلامي فيها نصيب كبير. وقد كان لتلك المدارس التي تعلم العلوم العصرية بالإضافة إلى تقديم الدين بصورة غير مباشرة دور بالغ في نشر أفكار غولان وبالتالي نشر الفكر الإسلامي بروحه المتسامحة ونظرته المنفتحة على الناس جميعاً. وقد عمد في ذلك إلى استغلال معرفته بالكثير من رجال الأعمال الذين دعاهم للاستثمار في هذا الميدان. ولعل سهولة خطاب غولان المبني على مقولة مهمة وهي أن التعلم وسيلة للحداثة وليس ضد الحداثة وأن التعليم وبعده عن التدخل في الشؤون السياسية للدول المضيفة لمدارسه ونجاح 
تلك المدارس على المستوى العالمي من خلال مشاركتها في مسابقات دولية، كان سبباً من أسباب نجاح تلك المدارس التي أصبحت أمكنة يتعلم فيها أبناء الطبقة الحاكمة في مجتمعاهما.

ولم يسلم غولان من نقد العلمانيين له واتمامه بالرجعية والعودة إلى العثمانية كمرحلة في حياة الشعب

التركي. ويعلق على كلمة الرجعية فيقول" إن كلمة الرجعية تعني العودة إلى الماضي أو إحضار الماضي إلى الحاضر. إنني شخص جعل الآخرة هدفه وليس الغد فقط. أنا أفكر بمستقبل بلدنا وأعمل كل ما بوسعي لتحقيق ذلك. لم أفكر بإعادة بلدي إلى الماضي في أي من كتاباتي أو أحاديثي أو أنشطتي، لكن أحداً لا

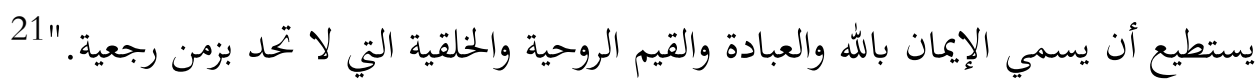

\section{العلاقة مع الآخر : العلاقات الدولية من منظور إسلامي: التسامح والحوار}

يعتقد الشيخ غولان بالتعددية والتسامح ويرى أن طبيعة المجتمع التركي والذي نشأ في ظلال الدولة العثمانية بجتمع منفتح بطبيعته ومؤمن بالحوار والتسامح مع الآخر. ولذلك فهو كثيراً ما يشير إلى ذلك مستخدماً عبارة الإسلام التركي. وفي هذا الصدد يقول: "الإسلام التركي يتشكل من المبادئ الإسلامية الأساسية التي لا تحتمل التبديل والتغيير والمنطلقة من القرآن والسنة. ولذلك فالإسلام التركي أكثر انفتاحاً

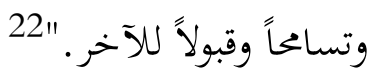

ولأن غولان ينطلق من فهمه للتسامح من القرآن والسنة، فهو يشير في أكثر من موقع إلى الحديث المشهور "الناس سواسية كأسنان المشط". والحديث الآخر "كلكم لآدم و آدم من تراب...". ويعتقد أن "النظام الاجتماعي الإسلامي يسعى إلى تحقيق مجتمع الفضيلة فيرضي بذلك الله سبحانه وتعالى. فهو يعترف بالحق لا بالقوة لتحقيق الحياة الاجتماعية. ولذلك فالعلاقة يجب أن تبى على الحب والاحترام المتبادل والفهم

21 In Michel. Ibid., p., 77

22 Ünal A \& Williams, A. (eds). The advocate of dialogue: Fathallah Güllen. 2000, p. 54-56. In Yavuz \& Esposito. Ibid. p., 223. 
بدلاً من الصراع والسعي لتحقيق المصالح الفردية..". 23 أما ما ورد في القرآن عن اليهود والنصارى، فهو يعتقد بأن المقصود هم الذين عاشوا خلال الفترة النبوية والذين وقفوا موقفاً معيناً من الدعوة."24 هذه الدعوة للتسامح يجب أن ينظر إليها في السياق الإسلامي العام وليس في السياق التركي الخاص. فالإسلام منذ بداياته الأولى حض على التسامح والاعتراف بالآخر وعدم إكراه الناس على الدين. والحوار مع الآخر موجود في سيرة النبي الكريم عليه السلام كما هو أصلاً في القرآن الكريم كما في قصص الأنبياء مع أقوامهم وأهليهم. قد حفل التاريخ الإسلامي بحوارات كثيرة بين المسلمين وأقوام شتى. فمن المعروف أن الإسلام جاء ليخرج الناس كل الناس من عبادة الطواغيت والعباد إلى عبادة الله سبحانه وتعالى وحده. هذا الهدف العظيم استدعى من المسلمين أن ينساحوا في الأرض فيبلغوا دعوة الله. ولما كان الطواغيت والملأ من ورائهم لا يحبون الحق ولا ينصاعون إليه بسهولة، فقد وقفوا في وجه الدين الجديد مدافعين عن مصالحهم المادية وعروشهم مستخدمين شعوبهم المغلوبة على أمرها.

والمعروف أن الرسول الكريم صلى الله عليه وسلم أرسل الرسائل الكثيرة لزعماء العالم في أيامه. فبعث برسالة إلى كسرى ملك الفرس وهرقل ملك الروم وهما زعماء العالم آنذاك. كما كتب إلى النجاشي والمقوقس ملك مصر وغيرهم. وقد استخدم الرسول الكريم لغة النبوة التي تنضح بالأدب النبوي والتي هدف إلى كسب قلوب أولئك الناس إلى الدين الجديد. وقد كان الرسول يحمل رسائله إلى نفر من الصحابة الكرام. فقد اختار صلى الله عليه وسلم عبد الله بن حذافة السهمي ليحمل كتابه إلى كسرى ملك الفرس. وقد رد كسرى رداً قبيحاً متجاوزاً كل القيم الديبلوماسية فمزق كتاب رسول الله صلى الله عليه وسلم، فلما بلغ ذلك الرسول الكريم دعا عليه قائلاً " مزق الله ملكه" وكان أن انقلب على كسرى ابنه شيرويه.

ومن الحوارات المهمة في التاريخ الإسلامي تلك المساجلة التي جرت بين الصحابة رضوان الله عليهم إثر وفاة الرسول صلى الله عليه وسلم. أما بعد النبوة، ففي معركة القادسية، أرسل سعد بن أبي وقاص رضي الله عنه الصحابي الجليل عبادة بن الصامت إلى ملك الفرس. ودار بينهما حوار سجلته كتب التاريخ.

23 Güllen, M. Fethullah. "A comparative Approach to Islam and Democracy". SAIS Review (2001a) $2: 133-138$.

24 Yilmaz, I. Ijtihad and Tajdid by Conduct. In Yavuz \& Esposito. Ibid p. 230. 
وملخصه أن الإسلام دين جاء ليخرج الناس من عبادة العباد إلى عبادة الله وحده ومن ضيق الناس إلى سعة الدنيا و الآخرة ومن جور الأديان إلى عدل الإسلام. ولذلك ليس من العدل أن يقال بأن شعباً مسلماً بعينه اختص بهذه المزية دون غيره.

وقد كان لحركة غولان أنشطة كثيرة في محاولاتما للحوار مع الآخر متمثلاً في دعوات الإفطار التي تنفذها وتدعو إليها الكثير من الشخصيات الدينية والعلمانية من أجل فتح حوار يخدم البلاد. وقد كان لغولان نفسه نشاط كبير توجه بلقاء البابا في الفاتيكان والكثير من الشخصيات الدينية الأخرى.

\section{خاتمة:}

في هذه الورقة تناولنا بالوصف والتحليل إحدى الشخصيات الإسلامية العاملة على الساحة التركية وهي شخصية الشيخ فتح الله غولان. فهذه الشخصية التي قامت في إثر حركة النور التي أسسها الشيخ سعيد النورسي قدمت العديد من المفاهيم الجديدة على العمل الإسلامي. ولعل خصوصية المكان والزمان لعبا دوراً بارزاً في تلك الدعوة. فالشيخ غولان ليس شيخاً تقليدياً بالمعنى الحريف للكلمة، ولا شيخ طريق صوفية ولا هو بالسياسي الإسلامي، بل هو مزيج من ذلك كله، وإن كان أظهر ما في شخصيته الوعظ والتربية على الإسلام.

لقد قدم الشيخ نموذجاً فريداً للعمل الإسلامي في ظل ظروف بالغة الصعوبة. وقد استطاع أن يسير في عمله وحركته بعيداً عن المحن والابتلاءات التي واجهتها الكثير من الحركات الإسلامية في المشرق العربي تحديداً. وذلك باعتقادنا لفهم الشيخ لطبيعة المكان: الدولة التركية العلمانية التي ما فتئت تحارب كل أشكال التدين. وفهمه ذاك ساعده على الانطلاق إلى العالمية من خلال تبنيه لفكرة مهمة وهي أن الدعوة للإسلام لا بد أن تسير وأن العمل مرتبط بالأمل.

إن الشيخ غولان في عمله هذا استطاع أن يجمع الكثير من التناقضات التي تبدو على السطح. فقد يؤيد الحكم التركي العلماني لقناعته بأن الدولة لا بد لها أن تحكم وأن البديل هو الفوضى التي رآها بعينه 
تصدع أركان البيت التركي في السبعينيات من القرن الماضي. ويستفيد من كل فرصة متاحة للعمل، فيستفيد من الانفتاح فيشير على تلاميذه بالاستفادة من تلك الأجواء، فتفتح البنوك الإسلامية، وتنشئ محطات الإذاعة و الثفلزة والمدارس والجامعات وبيوت النور . ولعل أهم ما يمكن أن يميز عمل الشيخ غولان هو البعد عن الجدل النظري الذي استحكم هذه الأيام وجعل الساحة الإسلامية ساحة جدل لا ساحة عمل. فآثر أن يترك الجدل إلى العمل وهو أمر لا بد أن تعيه الحركات الإسلامية بكل أطيافها وخلفياتا وتطلعاتا، فما

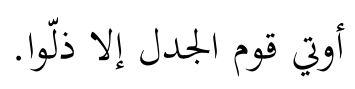

